\title{
O DISCURSO CINEMATOGRÁFICO EM SER- RA PELADA, A LENDA DA MONTANHA DE OURO, FILME DE VÍCTOR LOPES (2013)
}

\author{
ANA PAULA SILVA CÂMARA \\ UNIVERSIDADE DA AMAZÔNIA \\ BELÉM, PARÁ, BRASIL \\ ANAPAULASCAMARA@GMAIL.COM
}




\section{O DISCURSO CINEMATOGRÁfICO EM SERRA PELADA, A LENDA DA MONTANHA DE OURO, FILME DE VÍCTOR LOPES (2013)}

Resumo: O discurso cinematográfico se constitui como uma forma de aprofundar a combinação implicada na linguagem narrativa do filme documentário, no caso, como neste estudo, o filme Serra Pelada, a lenda da montanha de ouro (2013), de Víctor Lopes que demonstra como um acontecimento pode ser criado como memória, como se a imagem se tornasse tempo, ideia e pensamento através da descrição do filme.

Palavras-chave: discurso cinematográfico; interpretação do sentido; cinema real.

\section{EL DISCURSO CINEMATOGRÁFICO EN SERRA PELADA, LA LEYENDA DE LA MONTAÑA DORADA, PELÍ́CULA DE VÍctor LOPES (2013)}

Resumen: El discurso cinematográfico constituye una forma de profundizar la combinación implícita en el lenguaje narrativo del documental, en este caso, como en este estudio, la película Serra Pelada, la leyenda de la montaña dorada (2013), de Víctor Lopes que se demuestra como un evento. se puede crear como memoria, como si la imagen se convirtiera en tiempo, idea y pensamiento a través de la descripción del película.

Palabras clave: discurso cinematográfico; interpretación del significado; cine real.

\section{THE CINEMATOGRAPHIC DISCOURSE IN SERRA PELADA, THE LE-} GEND OF THE GOLDEN MOUNTAIN, FILM BY VÍCTOR LOPES (2013) Abstract: The cinematographic discourse constitutes a way of deepening the combination implied in the narrative language of documentary film, in this case, as in this study, the film Serra Pelada, the legend of the golden mountain (2013), by Víctor Lopes, which demonstrates how an event it can be created as memory, as if the image becomes time, idea and thought through the description of film.

Keywords: cinematographic discourse; interpretation of meaning; real cinema.

\section{INTRODUÇÃO}

"A dois bilhões e meio de anos dois pedaços da crosta terrestre se chocaram. Com o atrito, a temperatura e a pressão, o material acabou subindo para a superfície formando centenas de vulcões. Algumas reservas minerais, antes profundas ficaram praticamente expostas e sobre elas nasceu uma densa floresta. Aqui milhões de anos mais tarde seriam descobertas as 
maiores reservas de ferro e a mais rica montanha de ouro do planeta". Esta é a legenda do primeiro plano sequência do filme Serra Pelada, A lenda da montanha de ouro (2013), documentário de Víctor Lopes. No 7:08 (sete minutos) iniciais do filme, o geólogo Breno dos Santos narra sobre as imagens aéreas de uma esfumaçada floresta. Possivelmente seria a representação do processo de formação geográfica de uma montanha de minérios, a narrativa fílmica sugere a formação da Serra Pelada, em Eldorado do Carajás.

Arlindo Machado escreveu no prefácio do livro Discurso cinematográfico (2005), de Ismail Xavier que o termo enquanto teoria é de fundamental importância quando se pretende estudar, ou mesmo analisar cinema pela compreensão sintética do autor em aplicar tal conhecimento enquanto linguagem compreensível que permite ter densidade e complexidade ao conceituar às mudanças constantes do processo inicial do cinema na a partir dos anos 70. Com a recepção, a posição, a subjetividade e afetos seria possível observar teoricamente e analisar perspectivas e abordagens que poderiam vir a modelar o sujeito isento da capacidade crítica, poderia vir a influenciar o espectador, tornando o público apto a assumir tais construções subjetivas apresentadas em filmes.

Tais temas até os dias de hoje merecem da crítica a atenção, quando tratar de comprometer teorias e análises com ideologias que influenciam as concepções sobre pensamento e sociedade como: marxismo, feminismo e multiculturalistas, que na década de 70 tinha o nome de "dispositivo" por conta da característica de modelo influenciador do imaginário, porém que recebiam intensa averiguação pela acusação de fazer com que o público se aproprie das representações constituídas nos filmes.

O principal pensamento teórico de Xavier (2005) é o "desconstrucionismo" como crítica e perspectiva de análise mesmo que muitos filmes "comerciais" e hollywoodianos tenham sido produzidos em grande quantidade desde 1970.

No sentido da interpretação e "desconstrução" este trabalho propõe uma discussão sobre Discurso cinematográfico a fim de conceber problemáticas e concepções que consideram sistemas como: recepção porque tratam a comunicação, pelo aparato do "texto" cinematográfico por que constitui história e discurso enquanto ordem da palavra do discurso.

\section{DISCURSO E ORDEM DE CONSTRUÇÃO HISTÓRICO: O PODER}

Para Foucault a importância que a palavra tem para a construção his- 
tórica na realização do discurso está na necessidade de considerar o que é comum e irônico.

O percurso na prática e materialidade é como uma coisa pronunciada e escrita. Como no teatro, o discurso advém da fonte de valor; da exclusão, de interdição, do político. A relação entre poder e desejo como o discurso e sua ordem são expostos e tem como referências metafóricas o uso das palavras no discurso em comparação com a psicanálise.

Da origem da exclusão; separação e rejeição versus razão e loucura. Como referência a loucura pode ser identificada através do discurso que está distante do proposto pelo outro, de forma incoerente também revelar verdades inauditas. Então a palavra do louco encontrou no teatro, por exemplo, o lugar do acolhimento porque representaria o local ideal para se dizer a verdade com o rosto coberto pela atuação.

Enquanto desejo, o discurso exerce o domínio de satisfação de um em detrimento do outro; parte daí então a categorização do poder. Eis então que possivelmente a verdade e falsidade são observadas como princípios expostos na contextualização do discurso.

Ainda no contexto da verdade, o discurso de verdades pode vir a ritualizar uma tendência à justiça e institucionalidade. Pedagógica no sentido de como será aplicada à sociedade. Foucault denomina o estruturalismo na construção do discurso da verdade nos percursos das ciências no sistema da exclusão e seus três pontos: a palavra proibida; a segregação da loucura e a vontade da verdade. A permanência neste último tema referenciando a uma necessidade social, do controle, procedimento na ordem da classificação definindo-o e categorizando o discurso de acordo com narrativa da sociedade em movimento, nos fatos, no âmbito da cultura e em certos, nos estatutos do conhecimento científico e a relação com os aspectos enunciados.

"Esmeraldas, diamantes. Dois tipos de ouro, ouro branco e ouro amarelo" (fala de um personagem não identificado no filme)

De acordo com Fernandes (2003, p. 8) A ordem do discurso propõe analisar os conjuntos literários, religiosos, éticos, médicos, jurídicos. Investigar os sentidos e usos na sociedade. Mas é válido para as artes, comunicação e cinema por contemporaneidade.

Relacionar as práticas discursivas e não-discursivas entre séries discursivas e interdiscursividade levados na Análise de Discurso - acontecimento discursivo como análise ininterrupta da história dos enunciados.

Uma descrição metafórica é descrita através da leitura sobre uma poesia 
que se refere a objetividade partilhada junto a subjetividade da relação do homem com meio material no sentido em que o tema deste estudo possa ajudar a determinar inconscientes, determinações sociais condicionadas pelo inconsciente que sugerem intenção estruturalista de autoria da obra.

A intencionalidade desta discussão é avançar para a noção do sujeito mediante as perspectivas de problemas entre sujeito/autor.

O ser social surge com associação de pensamento e ação. Prévia de ideia onde a ação é antecedida pela ideia. Uma nova linguagem estabelecida pela leitura do mundo através do pensamento. Linguagem como consciência.

Sobre a concepção Marxiana da subjetividade é exposta a problemática que afirma ser parte da prática discursiva - a esta subjetividade - a necessidade de ser compreendida a partir das contradições humanas. Duas categorias estão dispostas: subjetividade e objetividade. Objetividade e subjetividade não se separam do ser humano quanto ao pensamento de busca pelo conhecimento e vive a realidade. Universalidade e singularidade e a relação com a apreensão cognitiva.

À coisa em si correspondente ao objeto e a lógica das coisas e a segunda ao sujeito cognoscente. É através do processo de busca pelo conhecimento, apreensão do real, por este sujeito que se busca pelos conceitos em movimento e suas estruturas lógicas.

A origem dessa busca do conhecimento advém do conceito ideológico de que o ser social exerce na ação com a sociedade.

O primeiro e o segundo pilar de Teorias linguísticas (FERNANDES, 2003, p. 6) podem ajudar a ilustrar como se estabelece a problemática da discussão entre Discurso cinematográfico, análise de discurso e sujeito do discurso como proposto no escopo de trabalho:

- Primeiro pilar é o de Louis Althusser

A vida social, política e intelectual são dominadas pela produção material, a base de dominância e dominação. Ideologia é uma condição da materialidade; arbitrária, orgânica. Formação social, determinam lugar e lutas, e estão ligadas às instituições (aparelhos ideológicos: Estado). Universais, individuais, de conflito podem ser formações discursivas por conjunturas.

- O segundo pilar: Michel Foucault

Os conceitos são esmiuçados em:

a) Práticas, saberes, formação de discursos; 
b) Dizeres e fazeres;

c) Enunciação (jogos) e enunciados (unidade básica linguística);

d) Estratégia, momento histórico;

e) Quem fala, fala de algum lugar, a partir de um direito;

f) A produção do controle, da seleção, organizada e redistribuída;

E de acordo com o que se quer estudar sobre cinema é possível encontrar diversas linguagens. A narrativa do filme como estudo do cinema poderá vir a ser a escolha que justificará.

As divergências sobre as interpretações que precederam o sentido de categorizar as narrativas produzidas nos filmes dos Lumière em que os críticos, no caso, jornalistas da época conferiam ao cinema produzido quanto à função social, por exemplo. Como estilo sugeriram como a máquina que registraria arquivos, além de ferramenta importante de auxílio à pesquisa e educação. Ou mesmo um aparelho de distribuir histórias, ou o próprio fato de o encontro do cinema com a narratividade ter favorecido a história, a sociedade, ou mesmo de civilizações como utilizam enquanto formato da etnografia (importante para o sociólogo Marcel Mauss).

Com o avanço e surgimento de novas técnicas o cinema da realidade semiológica sofre as mudanças quanto a linguística por conta de outras línguas e fatos históricos que refletem como o cinema funcionou e por que. Os documentários ficaram à margem daqueles chamados de filmes. Portanto, na realidade, o real ficou cada vez mais evidente enquanto expressão fílmica.

\section{CRONOLOGIA DO PENSAMENTO}

- O terceiro pilar: Mikahil Bahktin:

Bahktin incorpora a recepção e repercussão dos estudos literários aos linguísticos. As reflexões de gênero, polifonia, cronotopo, carnavalização, formas de incorporação do outro à linguagem, definição do "outro" bahktiniano, vozes, etc.

Para Brait (2001) as obras de Marx e a filosofia da linguagem por conta da apresentação do signo, como luta de classes de dimensão histórica, social e cultural da linguagem; do conceito do gênero.

A função linguística como uma semiologia deveria ser a proposta de Saussure como precursor da ciência da linguagem. O modelo bahktiniano tem base na interação e Pêcheux pensava que não deveria pensar o sentido na esfera interindividual. 
Lacan atravessa caracterizando a psicanálise como um fundamento para o trabalho (Pêcheux) com conceitos: "formações imaginárias", de "simbólico" e "inconsciente".

Controle e vigilância sobre as produções verbais. As atividades comuns do dia a dia de trabalho, casa, etc., se apoiam em técnicas de coleta, exploração e interpretação de dados verbais. Se multiplicam através dos meios de comunicação. Seguem ordem psicoterapêuticas, incitam sujeitos às expressões. Estas estarão por sua vez aquém de avaliação e análises dos especialistas que tratam de estabelecer formas de estudos de como o mundo controla e vigia sobre as produções verbais. As atividades comuns do dia a dia de trabalho, casa, etc., se apoiam em técnicas de coleta, exploração e interpretação de dados verbais. Se multiplicam através dos meios de comunicação. Seguem ordem psicoterapêuticas, incitam sujeitos às expressões. Estas estarão por sua vez aquém de avaliação e análises dos especialistas que tratam de estabelecer formas de estudos de como o mundo reflete pelas falas. Os estudos do discurso convergem de variadas correntes de pesquisas e disciplinas exercendo influência sobre elas.

Esta "virada linguística" que apelam entre si por suas problemáticas, conceitos e métodos podem identificar as categorias, métodos de análise e a tomada de consciência da pluralidade do discurso. Ajudar a delimitar terminologias e métodos.

Primeira parte do estudo do discurso: história, definição de termos como discurso ou texto, e grandes divisões de estruturas.

Segunda parte: estudos das unidades com base nos trabalhos dos analistas; (gênero, tipo de discurso, formação discursiva, ou seja, construção de objetos).

Terceira parte: ao mesmo tempo, unidades e diversidade do universo do discurso e regimes de fala. Estudos do discurso se diferenciam de análise, posto que análise parte de um ponto específico de visão.

\section{PROCEDIMENTOS METOdOLÓGICOS}

Como o projeto de um estudo exploratório e qualitativo, este artigo através da natureza do objeto procura pontuar observação e busca um entendimento de ligação entre o tipo de cinema produzido em A lenda da montanha de ouro (2013), de Víctor Lopes como cinema documental e Discurso cinematográfico através da definição do tipo de cinema, da dinâmica de referência de algumas imagens do filme considerando a interlocução com 
outras ordens teóricas de estudos sobre Discurso e reflexão de contexto e perspectivas de mediações imagéticas quanto ordem e análise de citações.

A relação de proximidade com a realidade, talvez sugerida pelo contexto e mediada pelas imagens do filme são a forma como o cinema é realizado. Necessário relembrar que o olhar humano capta de forma natural posto que o que é perceptível através do que se apresenta no mundo exterior. Formada por conjunto de imagem e som, como elementos de comunicação da fílmica que o espectador, o público junto ao seu repertório lê através de códigos e interpreta através dos sentidos.

Quanto a estes sentidos físicos estimulados pelo filme é possível fundamentar os conceitos do discurso assim como na montagem do cinema, as sequências das imagens fílmicas que se fixam quanto a gramática da língua, a linguagem que conferem o sentido absoluto que é recebido pelo espectador, pelo público. O quadro fotográfico assim como outros mecanismos do processo fílmico que remetem ao realizador no engendrar o texto audiovisual a forma como no texto escrito.

Melhorar a compreensão e relação com o texto e situações sócio históricas.

Análise automática do discurso de Pêcheux usava a psicologia social como laboratório já que não participou da revista francesa Language por diferenciar com seu projeto de estudos, por ser um filósofo marxista.

Decompor os textos revelariam as ideias, como na psicanálise. A influência de A Arqueologia do Saber de Foucault que se apresentariam como vocabulário, sintaxe, estrutura lógica, ou organização teórica. E esta última assim como as estratégias interacionais devem estar no cerne principal da análise.

Sobre a imprensa escrita (2007). Maingueneau (1984) discurso religioso ou literário (1993). Todos classificam-se como gêneros dos estudos de análise do discurso com base na linguística. Ao mesmo tempo, nos Estados Unidos também se difundem na França através das conversas de Kerbrat-Orecchioni (1990-1992). (MAINGUENEAU, 2015, p. 21).

O discurso enquanto linguagem interagiram com a ideia das ciências sociais à filosofia da linguagem ordinária (Wittegenstein) e a teoria da fala (Austin e Searle) e a concepção do sentido (Grice), interacionismo simbólico (Mead), a etnometodologia (Garfinkel), a escola de Palo Alto (Bateson), o dialogismo de Bakhtin, a psicología de Vigotsky, a arqueologia e a teoria do poder de Foucault, do pós-estruturalismo de Derrida, Deleuze, Lacan, La- 
clau, Butler, das correntes construtivistas, às sociologia do conhecimento de Berger e Luckmann (de A construção social da realidade, 1966). Do leitmotiven, de ideias-forças.

Pensar o discurso como constrói socialmente o sentido, que articula espaços disjuntos: "realidade e língua”, "entre as palavras e as coisas".

Sentidos, sujeitos, lugares, unidade, diversidade. Discurso é ritual de palavra. As relações entre sujeitos e os sentidos mais a linguagem com o mundo. Toda a formação de social, formas de controle de interpretação que dependem da forma de interpretar, do corpo social que delegam poderes de interpretar, atribuir sentido como os papéis dos profissionais como juiz, professor. O fato enquanto objeto simbólico e o processo de interpretação. Fatores como o ser social se comunica com a linguagem no cotidiano, este serão os temas do conteúdo deste trabalho.

Uma proposta de reflexão no contato com os princípios e procedimentos analíticos sobre discurso expostos e em contrapontos à linguagem com o mundo, com os sujeitos, com os sentidos, com a história. (ORLANDI, 2005, p. 11)

O filme documentário tem por este motivo a composição do objeto deste artigo. Documentários tem a perspectiva da linguagem do registro do sentido enquanto forma de revelar, de um ponto de vista, no caso do diretor, o discurso ou os discursos a respeito de um episódio, de um fato, acontecimento por característica do real, a histórica que se identifica pelo modo como é realizado: depoimentos de personagens reais, pessoas que argumentam a veracidade da história ocorrida e legitimada através da imagem como se estabelece a construção simbólica no discurso cinematográfico.

A língua no mundo, com as maneiras de significar, com homens falando, produções de sentidos, partes das vidas, a sociedade. A história, os processos e condições da linguagem, a análise da relação entre língua e sujeitos que falam situações do dizer. $\mathrm{O}$ analista estudou a linguagem relacionada com a exterioridade. Um modo particular dos Campos das Ciências Sociais e do domínio da Linguística. Reflexão sobre a história da epistemologia, filosofia e conhecimento empírico. Tal articulação objetiva que transforma a prática das ciências sociais e dos estudos da linguagem.

Os estudos discursivos pensam o sentido dimensionado no tempo e no espaço das práticas do homem, descentralizando o sujeito e relativizando o objeto da Linguística. 


\section{UMA ANÁLISE DO DISCURSO CINEMATOGRÁFICO}

Esta é uma análise do filme A lenda da montanha de ouro, (2013) de Víctor Lopes como todo. De um cinema do tempo, da linguagem do discurso cinematográfico realizada a partir dos aspectos sensórios-motores descritos por Gilles Deleuze em A imagem-tempo de (1990) em que para o olho de quem vê (ou assiste ao filme) tem-se como referência a "literalidade" do mundo legível e que se ligam às relações internas subordinadas à sensível descrição de um espaço e de um pensamento que formam o conjunto de funções como cita Deleuze Hitchcock: "uma consciência câmera" seguidas pelas relações mentais que estabelece ao questionar, responder, provocar e experimentar a relação pensamento-cinema-verdade: a verdade do cinema. (DELEUZE, 1990, p. 34).

Separados em: aspectos visuais, a imagem óptica, da imagem lida, não somente vista (o que está representado na imagem movimento, como o filme é percebido); a imagem sonora (som direto do filme: as vozes, trilha sonora) e (táctil) pura.

Agora em segurança das abordagens da imagem-tempo, da imagem-legível, e imagem-pensante junto às relações com elementos interiores a necessidade de decifrar e compreender como uma transferência de informação dos significados de um sujeito a outro ou mesmo de um filme ao sujeito aproxima mais de leitura do que a própria percepção.

Importante ressaltar que O filme Serra Pela lenda da montanha de Ouro (2013) foi filmado ao longo de 11 anos pelo diretor Víctor Lopes, as filmagens foram iniciadas. O início da extração do ouro na Serra Pelada data 1980. Entre o fato a de tempo entre realidade-fato (1980), início das filmagens (2002) e o filme finalizado totaliza cerca de 15 anos.

Necessário fazer a recapitulação das imagens assim como a leitura dos signos do cinema no filme e que a partir da indagação de Metz é: Como a imagem substituiria a imagem por um enunciado, como o enunciado de uma linguagem que pode vir a ser somente visual independente de uma língua? Mas sim o que é possível encontrar no cinema são traços da linguagem que se adaptam aos enunciados. Seria como se a semiologia (o estudo dos signos e significados dos ritos e costumes além dos sistemas de comunicação da sociedade) do cinema fosse a disciplina que relacionam o que está expresso no filme através das imagens percebidas e incorporadas.

O simbólico é uma área essencial para estes estudos. Evitar o equívoco 
de perceber neutralizado o uso dos signos. Uma vez dentro do simbolismo, não há retorno, nem saída. O compromisso é com o sentido e o político. Interpretar e tentar criar uma relação com a linguagem. (ORLANDI, 2005, p. 9)

Sobre o ouvir e ver torna o discurso credível, seja pela atribuição da confiança do carisma ocasionado pela identificação no processo de construção da imagem do falante uvir e ver torna o discurso credível, seja pela atribuição da confiança do carisma ocasionado pela identificação no processo de construção da imagem do falante.

O sujeito falante recorre a: emoção e sentimentos que de forma seduzirá ou provocará temor ao interlocutor - dramatização - é o nome do apelo discursivo que se estabelece nesse sentido.

A fala como organização do mundo proposto ou imposto: retórica, narrativa e argumentação. Racionalização e logos também como processos na construção de tais elementos essenciais a discursividade:

O sujeito falante recorre a: emoção e sentimentos que de forma seduzirá ou provocará temor ao interlocutor - dramatização - é o nome do apelo discursivo que se estabelece nesse sentido. Aqui a problemática do pathos.

A fala como organização do mundo proposto ou imposto: retórica, narrativa e argumentação. Racionalização e logos também como processos na construção de tais elementos essenciais a discursividade:

\section{Situação de comunicação}

(dispositivos/visadas)

(instruções discursivas)

$\underline{\text { Sujeito » estratégias » Credibilidade/capacitação }}$

(contato/relação)

(imagem/ethos)

(emoção/pathos)
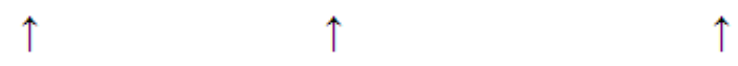

Organização retórica (narrativa / argumentativa)

(logos) 


\section{CONSIDERAÇÕES FINAIS}

A partir do levantamento teórico e analítico a reflexão cabe compreender de que o cinema representado como objeto (Serra Pelada, a lenda da montanha de ouro, de Víctor Lopes) as imagens são como um mundo, o mundo em particular de uma história específica com traços de extensão da literalidade como a língua, como a escrita do documento, como um registro próprio que funciona como objeto real como tal qual um objeto virtual ao mesmo tempo por que envolve e reflete tal realidade pelo discurso, por um tipo de discurso, o discurso cinematográfico.

Seja pela formação e reconhecimento de uma imagem de uma captura de um fato real, mas que faz com o termo caiba para descrever ou criar uma memória como o pensamento que propunha uma comunicação com o verdadeiro, com o que está presente, ou enunciado que pretende conservar o tempo, a imagem-tempo como fundamento oculto. Como se a imagem formasse uma persistência para poder compreender as imagens, a linguagem e o pensamento.

Para tanto o cinema através das imagens organiza de forma coexistente; como o início do filme, a ideia para formar imagens que correspondam exatamente como se diferencia passado, atualidade e que substituímos por esta vista ótica-sonora como se fosse a possibilidade de retratar o mundo, a vida, o episódio como único.

\section{REFERÊNCIAS}

CHARAUDEUA, Patrick. O Discurso propagandista: uma tipologia. Disponível em: < https://bit.ly/2KA7OXE >

FERNANDES, C. SANTOS, J. B. (org.). Teorias linguísticas: problemáticas contemporâneas. Uberlândia: UFU, 2003. Disponível em: <https://drive.google.com/file/d/oB7of8DSvP60Jd2ZqMUgxZEdXeko/view>.

FOUCAULT, Michel. A ordem do discurso. Edições Loyola. Tradução: Laura Fraga de Almeida. São Paulo, Brasil, 1996.

MAINGUENEAU, Dominique. Discurso e análise do discurso. São Paulo: Parábola Editoral, 2015. (p. 9-65 e 169-183).

MAGALHÃES, Belmira. 0 sujeito do discurso: um diálogo possível e necessário. Linguagem em (dis)curso, v. 3, p. 73-90, 2003. Disponível em: <https://bit.ly/2MkvpxA>.

METZ, Christian. A significação do cinema. Editora da Universidade de São Paulo. Editora Perspectiva. 1972. Disponível em: <https://edisciplinas.usp.br/pluginfile.php/149373/mod_ resource/content/1/ASIGNIFICACINEMA.pdf $>$. 
CADERNOS DE COMUNICAÇÃO

UNIVERSIDADE FEDERAL DE SANTA MARIA

ORLANDI, Eni. Análise de discurso: princípios e fundamentos. Campinas: Pontes, 2005.

XAVIER, Ismail. O discurso cinematográfico: a opacidade e a transparência, $3^{\text {a }}$ edição São Paulo, Paz e Terra, 2005. 


\section{Ana Paula Silva Câmara}

Mestre em Comunicação, Linguagens e Cultura pela Universidade da Amazônia (2021). Possui graduação em Gestão e Produção de Eventos Culturais pela Universidade da Amazônia (2002) e graduação em Publicidade e Propaganda pela Universidade da Amazônia (2016). Atuando principalmente nos seguintes temas: propaganda e cinema.

E-mail: anapaulascamara@gmail.com 